University of Nebraska - Lincoln

DigitalCommons@University of Nebraska - Lincoln

USDA Forest Service / UNL Faculty Publications U.S. Department of Agriculture: Forest Service -National Agroforestry Center

2016

Examining heterogeneity and wildfire management expenditures using spatially and temporally descriptive data

\author{
Michael S. Hand \\ USDA Forest Service, mshand@fs.fed.us \\ Matthew P. Thompson \\ USDA Forest Service \\ David E. Calkin \\ USDA Forest Service
}

Follow this and additional works at: https://digitalcommons.unl.edu/usdafsfacpub

Hand, Michael S.; Thompson, Matthew P.; and Calkin, David E., "Examining heterogeneity and wildfire management expenditures using spatially and temporally descriptive data" (2016). USDA Forest Service / UNL Faculty Publications. 297.

https://digitalcommons.unl.edu/usdafsfacpub/297

This Article is brought to you for free and open access by the U.S. Department of Agriculture: Forest Service -National Agroforestry Center at DigitalCommons@University of Nebraska - Lincoln. It has been accepted for inclusion in USDA Forest Service / UNL Faculty Publications by an authorized administrator of DigitalCommons@University of Nebraska - Lincoln. 


\title{
Examining heterogeneity and wildfire management expenditures using spatially and temporally descriptive data
}

\author{
Michael S. Hand*, Matthew P. Thompson, David E. Calkin \\ USDA Forest Service, Rocky Mountain Research Station, Missoula, MT, United States
}

\section{A R T I C L E I N F O}

\section{Article history:}

Received 7 July 2014

Accepted 7 January 2016

Available online 19 February 2016

\section{JEL classification:}

Q23

H11

\section{Keywords:}

Wildfire

Suppression expenditures

Heterogeneity

Cost models

\begin{abstract}
A B S T R A C T
Increasing costs of wildfire management have highlighted the need to better understand suppression expenditures and potential tradeoffs of land management activities that may affect fire risks. Spatially and temporally descriptive data is used to develop a model of wildfire suppression expenditures, providing new insights into the role of spatial and temporal heterogeneity in determining expenditures. Incorporating heterogeneity improves model fit and predictive ability over a model with data based on the point and time of fire ignition. The model is potentially useful for providing expenditure information for simulated fire applications and post-season evaluation of suppression activities.
\end{abstract}

Published by Elsevier GmbH. on behalf of Department of Forest Economics, SLU Umeå, Sweden.

\section{Introduction}

The escalating costs of wildfire management have been a persistent policy and land management problem for Federal agencies in the United States. Between 1992 and 2014 the proportion of the United States Forest Service's (USFS) annual budget devoted to fire management has risen from 13 to over 50 percent of total annual appropriations (http://www.fs.fed.us/about-agency/ budget-performance/cost-fire-operations). In response to this trend, the U.S. Government Accountability Office (GAO) and Department of Agriculture Office of Inspector General (OIG) have criticized

\footnotetext{
* Corresponding author at: 800 E. Beckwith Ave., Missoula, MT 59801, United States. Tel.: +1 4063292136.

E-mail address: mshand@fs.fed.us (M.S. Hand).
} 
the USFS and U.S. Department of Interior for their inability to quantify the value of investments in wildfire suppression (USDA OIG, 2006; GAO, 2009).

Much progress has been made toward understanding expenditures on wildland fire management activities, including insights into trends in suppression expenditures (Calkin et al., 2005) and the factors related to incident suppression expenditures (Gebert et al., 2007; Canton-Thompson et al., 2008; Liang et al., 2008; Gude et al., 2013; Donovan et al., 2011; Yoder and Gebert, 2012). Despite this progress, sophisticated expenditure models are increasingly needed to better forecast and manage agency expenditures, support outcome based performance measures, inform land, fire, and fuel management planning efforts, and support incident decision making. For example, prioritizing and planning treatments of hazardous fuels may incorporate the effect of treatment options on expected suppression expenditures (Taylor et al., 2013; Thompson et al., 2013c), and the Wildland Fire Decision Support System (WFDSS) uses a suppression expenditure model to provide information on expected expenditures for an incident under current conditions (Noonan-Wright et al., 2011). As these applications continue to be developed, expenditure models that can provide accurate information at the appropriate spatial and temporal scales will become increasingly important.

An important feature of many of the tools used for planning and decision support is the ability to generate spatially explicit information on biophysical and socioeconomic conditions related to wildfire. In WFDSS, a suite of fire modeling tools can provide detailed spatial information on likely fire behavior under different conditions, as well as the probable exposure of fire-susceptible assets such as built structures (Calkin et al., 2011; Noonan-Wright et al., 2011). Pre-fire analyses similarly consider how variability in environmental conditions can influence wildfire likelihood and intensity, as well as the potential consequences to resources and assets, with potential application for incident response planning and fuel treatment design (Scott et al., 2012a,b; Ager et al., 2013; Thompson et al., 2013a). Many of these fire models explicitly capture temporal variation in fire weather conditions that are driving factors in fire occurrence and behavior (Scott et al., 2013).

However, existing suppression expenditure models have not kept pace with advances in stochastic geospatial fire modeling. The empirical link between landscape and geographic characteristics and wildfire management expenditures has largely relied on geospatial data describing fire conditions at the time and place of ignition (Gebert et al., 2007; Donovan et al., 2011; Yoder and Gebert, 2012). Ignition-point data have to date been the best available data for investigating the determinants of suppression expenditures. ${ }^{1}$ With the availability of more detailed geospatial information about wildfires, including the widespread availability of digitized final fire perimeters, expenditure models can potentially incorporate data that provides a richer spatial and temporal description of characteristics that are related to expenditures. If spatial or temporal heterogeneity (or both) of these characteristics is related to expenditures, then ignition-point values will accurately represent this relationship only to the degree that the ignition point and time is representative of characteristics over the entire spatial and temporal extent of the fire. That is, models based on the ignition point alone cannot account for characteristics that exhibit spatial or temporal heterogeneity that may be related to fire behavior (e.g., topography, fuel conditions) or managers' responses to fire (e.g., land designation, proximal human development).

The goals of this study are two-fold: (1) to examine whether information on fire characteristics that vary over space or time can improve the fit and performance of suppression expenditure models over comparable models that use ignition-point data, and (2) to develop a suppression expenditure model that is capable of leveraging spatially explicit information generated by state-of-the-art decision support tools. To this end we develop a suppression expenditure model that can account for spatial and temporal heterogeneity throughout the evolution of wildfire incidents.

The primary empirical hypothesis is that spatially and temporally descriptive data may improve the accuracy and reliability of expenditure predictions by reducing measurement error and accounting for management responses to conditions that change over space and time. We investigate whether incorporating spatially and temporally descriptive data improves model fit and predictive power over

\footnotetext{
${ }^{1}$ An exception to the ignition-point approach is Liang et al. (2008), who incorporated spatially descriptive data for a sample of fires in western Montana and northern Idaho.
} 
existing models and yields any new insights about the factors associated with expenditures. We then illustrate how the model using spatially and temporally descriptive data can provide information in a decision-support framework that an ignition-point model is not capable of providing.

\section{Relationships between expenditures and heterogeneous fire characteristics}

Suppression expenditures are at a most basic level derived from decisions to deploy fire management resources to an incident. Strategic suppression decision making requires both spatial and temporal considerations as changing conditions may affect fire intensity, rate of spread, and resistance to suppression efforts. Over the course of a fire these changing conditions may influence fire manager decisions and expectations about resource needs, the aggressiveness of suppression activities, and the ability to safely deploy suppression resources. If managers respond to changing landscape and geographic conditions during a fire by changing the deployment of resources, then spatial and temporal heterogeneity of fire characteristics may influence expenditures.

Previous research on fire suppression expenditures has established that spatial and temporal characteristics measured at the time and place of fire ignition are related to expenditures (Gebert et al., 2007; Donovan et al., 2011; Yoder and Gebert, 2012). Landscape and geographic characteristics, such as fuel conditions and topography, are generally associated with fire behavior along with the accessibility and effectiveness of suppression activities. The risk to human communities is often a major driver of fire management decisions. Fire weather conditions and suppression effectiveness jointly determine fire behavior and associated risks throughout the course of an incident, leading to associated temporal dynamics in organizational needs and firefighting resource demands (Thompson, 2013).

Strategy choices selected by managers have also been shown to be related to the temporal dimensions of expenditures. More aggressive suppression strategies are associated with incidents that are shorter in duration and more expensive per acre; less aggressive strategies are associated with incidents that are longer in duration and less expensive per acre (Gebert and Black, 2012).

Missing from the literature on wildfire suppression and expenditures is an understanding of the determinants and cost consequences of managers responding to changing or heterogeneous conditions during an incident, or whether managers respond in ways that affect fire outcomes. Fire containment models are able to discern relationships between changing conditions and containment of a fire (e.g., Finney et al., 2009), but it is not clear what role management actions play in altering the path of the fire and affecting fire outcomes, or what the effect on expenditures may be. Studies that illustrate how strategy choices affect expenditures (Gebert and Black, 2012) and how conditions relate to strategy choices (Calkin et al., 2013) rely on cross-sectional variation rather than within-incident variation. Thus, it has not yet been established empirically that changing conditions or a heterogeneous landscape directly affects expenditures.

\section{Empirical approach}

Accounting for spatial and temporal heterogeneity in the independent variables essentially amounts to a measurement error problem. That is, the general empirical approach of this study is to more accurately describe the relationship between spatiotemporal characteristics and management expenditures by reducing measurement error. Measurement error in independent variables at best results in increased estimated error variances, and at worst results in inconsistent and biased regression estimates (Wooldridge, 2010, ch. 4). While possible deficiencies associated with measurement error have been known for some time (i.e., it has long been recognized that wildfire is a spatial contagion process whose evolution varies through time), only recently have improved geospatial data allowed such an econometric analysis.

The empirical hypothesis is that spatial variations in landscape and geographic characteristics, temporal variations in fuel moisture, and incident duration are related to management decisions during a wildfire which determine total management expenditures. Directly investigating this hypothesis would ideally require data that linked management decisions and resulting expenditures with the progression of spatial and temporal characteristics over the course of observed fires (e.g., a panel dataset of daily expenditure and fire characteristic observations). Such data would allow the researcher to 
observe how changes in conditions and geospatial characteristics of the fire are related to management actions, the deployment of suppression resources, and expenditures during the fire.

Although geographic information systems (GIS) techniques can provide detailed data on fire progression, administrative data on management decisions and expenditures over the course of a fire are not reliably available. Lacking an adequate panel data set (i.e., a cross-sectional time series), the empirical analysis instead leverages geospatial calculations of fire characteristics over the entire area within the final fire perimeter. The empirical model maintains the cross-sectional regression approach of previous studies that use ignition-point landscape and geographic characteristic data. But by substituting spatially and temporally descriptive characteristics calculated from the final fire area, observations of model fit, performance, and inferences can provide insight into whether heterogeneity of incident characteristics plays a role in determining expenditures.

If it is true that spatially and temporally descriptive data are able to account for management responses to conditions that change over space and time, thus reducing measurement error in the independent variables, then including this data in a cross-sectional regression model is expected to exhibit improved model fit (i.e., greater explanatory power) and performance (i.e., smaller prediction errors) compared with models using ignition-point data. Under the alternative hypothesis, using spatially descriptive data is expected to either not improve model fit or performance (e.g., because the spatially descriptive data introduces no new information), or fare worse due to the introduction of additional measurement errors (e.g., if ignition-point data are actually accurate descriptors of the conditions affecting management decisions).

To examine the effect of heterogeneous spatial and temporal characteristics on expenditures, we specify a regression model based on previous ignition-point suppression expenditures. The general form of the model can be expressed as:

$$
\ln \exp _{i}=\beta^{\prime} X_{i}+\varepsilon_{i}
$$

The dependent variable, $\ln \exp _{i}$, is the natural log of total federal (USFS and Department of Interior) expenditures during the $i$ th fire incident, expressed in constant 2012 dollars. The vector of $k$ independent variables $X_{i}$ (including a constant) includes characteristics that describe spatial variation or spatial averages over the entire burned area of a fire (e.g., vegetation and topography that are heterogeneous even over small areas and affect fire behavior), temporal variation during the time period when the fire was being actively managed (e.g., weather and fuel moisture characteristics that can change from day to day), and categorical variables that do not have a spatial or temporal component (e.g., geographic region where the fire occurs).

Our analysis differs from several studies on wildfire expenditures by focusing on total expenditures per fire incident rather than expenditures per unit of burned area. ${ }^{2}$ Total expenditures as a dependent variable is appropriate in this application because actual management efforts tend to consider conditions for the incident as a whole rather than on a per unit area basis. To illustrate this, consider the two fires depicted in Fig. 1 where detailed data on suppression activities were gathered. Among other characteristics, these fires differ in the amount and location of constructed fire control line, an indicator of suppression effort. The top panel (Chips Fire on the Plumas National Forest (NF) in California) shows aggressive suppression efforts in an attempt to control northeasterly fire spread that threatened communities along Lake Almanor. By contrast, the bottom panel (Halstead Fire on the Salmon-Challis NF in Idaho) depicts suppression effort concentrated along the southern flank while northward spread into a designated Wilderness area went unchecked.

The examples in Fig. 1 reveal several salient points that suggest total expenditures are more reflective of management practices related to suppression effort. First, containment efforts are typically directed along a portion of the free-burning perimeter and are not applied on a per-unit area basis. Second, the perimeter's size, shape, and location relative to landscape characteristics and valuable assets dictate where suppression effort is directed. Third, administrative boundaries within the Agency may influence the aggressiveness of the management strategy, the relative availability of resources,

\footnotetext{
2 Studies by Liang et al. (2008) and Hand et al. (2014, ch. 4) are exceptions, where the authors estimate models using total expenditures (not scaled by fire size).
} 

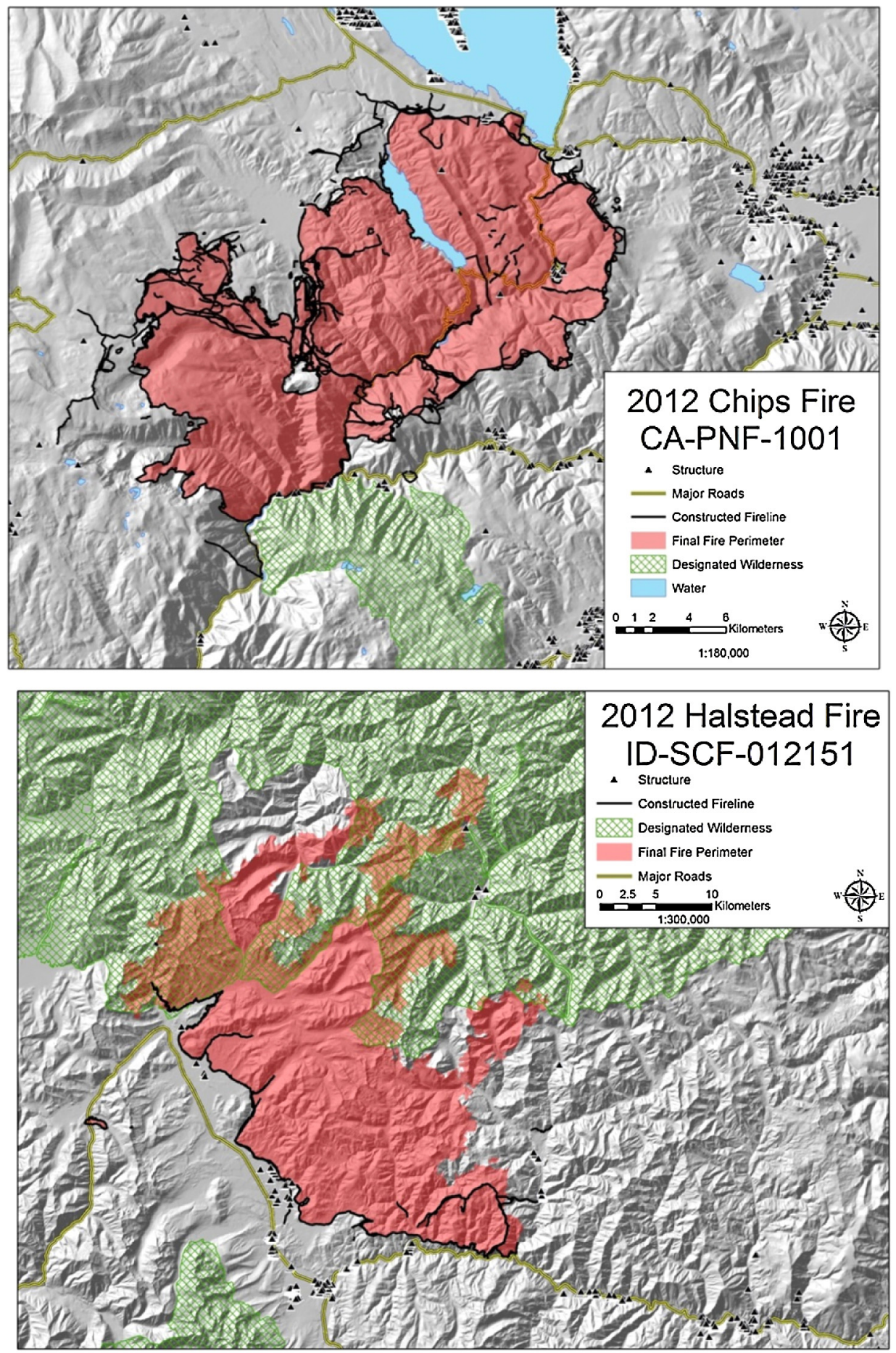

Fig. 1. Examples of wildfire management with differing containment strategies and effort. Source: RMRS analysis of incident geospatial data. 
and the unit cost of suppression available resources. Finally, spatial and temporal variation in burning conditions can affect the likelihood of containment (as evidenced by burned over fire line), which can potentially affect the demand for suppression effort. ${ }^{3}$

\section{Data on expenditures and fire characteristics based on the final fire perimeter}

The regression estimates are carried out on a sample of USFS large fires from fiscal year (FY) 2006 to FY 2011. A similar dataset was used in Hand et al. (2014, ch.4) to establish that spatially descriptive data could be used to explain expenditures across a broad geographic scope. Individual fire observations are drawn from the population of USFS large fires, defined as having an area of at least 300 acres (approximately 121 hectares), that have been analyzed for cost performance in previous years using ignition-point data. This initial list of fires contains 712 observations; we do not include in the analysis fires that are part of a "complex" (in which two or more fires are managed as a single incident, 123 fires) or occurred in the Eastern United States (Forest Service regions 8 and 9, 85 fires) ${ }^{4}$ - limiting the analysis to fires that occurred in the Western United States (i.e., Forest Service regions 1-6).

GIS calculations of the fire perimeter polygons yield the final burned area (in hectares) and other geospatial characteristics of each fire. ${ }^{5}$ In total, 504 fires that are included in the ignition-point data have useable final perimeters available. After data cleaning and eliminating records with missing or erroneous data, 406 fires are included in the estimation sample. ${ }^{6}$ Fig. 2 displays the geographic and size distribution of fires included in the analysis, and data descriptions and summary statistics are reported in Table 1.

A primary independent variable of interest is final fire size (In_hectares). Previous research has identified fire size as an important factor that is related to expenditures (e.g., Gebert et al., 2007; Liang et al., 2008). Controlling for size is important for this application because we may want to predict expenditures for fires when fuel treatments, past wildfires, or other changes to vegetative composition (e.g., through climate change impacts) have the potential to alter fire size, even when other observed landscape characteristics remain relatively unchanged. However, fire size and expenditures may be jointly determined if expenditures represent suppression effort that is effective at containing and arresting the growth of fires (i.e., more effort resulting in fires contained at smaller sizes; see Yoder and Gebert (2012) for theoretical development).

The exogeneity of fire size depends on fire size being uncorrelated with the error term in the expenditure regression (Eq. (1)). Theoretical and simulation studies of wildfire initial attack activities (i.e., efforts to quickly contain a newly-ignited fire) posit a role for suppression effort in controlling fire size (e.g., Parks 1964; Fried et al., 2006), ${ }^{7}$ although it is difficult to empirically parameterize this effect. In initial attack models (such as Fried et al., 2006), fire containment depends on the time until suppression resources arrive at the incident, the rate-of-spread of the fire, and the rate of fireline production. Two critical assumptions are necessary: (1) that dispatched resources build fireline that engages the fire, and (2) that the production of fireline (when it does engage the fire) is effective at containing a fire. These assumptions have faced only limited empirical scrutiny.

\footnotetext{
${ }^{3}$ Total expenditures is also econometrically convenient because it avoids specifying a dependent variable (expenditures per hectare) constructed from two potentially endogenous variables (expenditures and fire size). Thanks to an anonymous reviewer for highlighting this point.

${ }^{4}$ Complexes are difficult to analyze in a regression framework because some component fires may not have final perimeters available and expenditure data is not reported for individual component fires. Previous research has developed separate regression models for fires in Western and Eastern (Forest Service regions 8 and 9) regions to allow for different vectors of independent variables and different signs and magnitudes of estimated parameters (see Gebert et al., 2007). The development of spatially descriptive models for complex incidents or fires in the Eastern regions is left for future research.

${ }^{5}$ GIS calculations of burned area can vary slightly from reported size due to estimation errors or improved accuracy. Three fires in the final sample have calculated areas smaller than the 121 hectare definition of large fires, with the smallest being about 111 hectares (about 275 acres).

${ }^{6}$ The 98 fires eliminated because of missing or erroneous data tend to be overrepresented in the Northern Rockies and Pacific Northwest, and underrepresented in California relative to the estimation sample. These fires are also significantly smaller and less expensive on average compared to the estimation sample. However, the estimation sample appears to provide adequate statistical support for the range of observations not included in the sample.

7 Thanks to an anonymous reviewer for making this connection.
} 


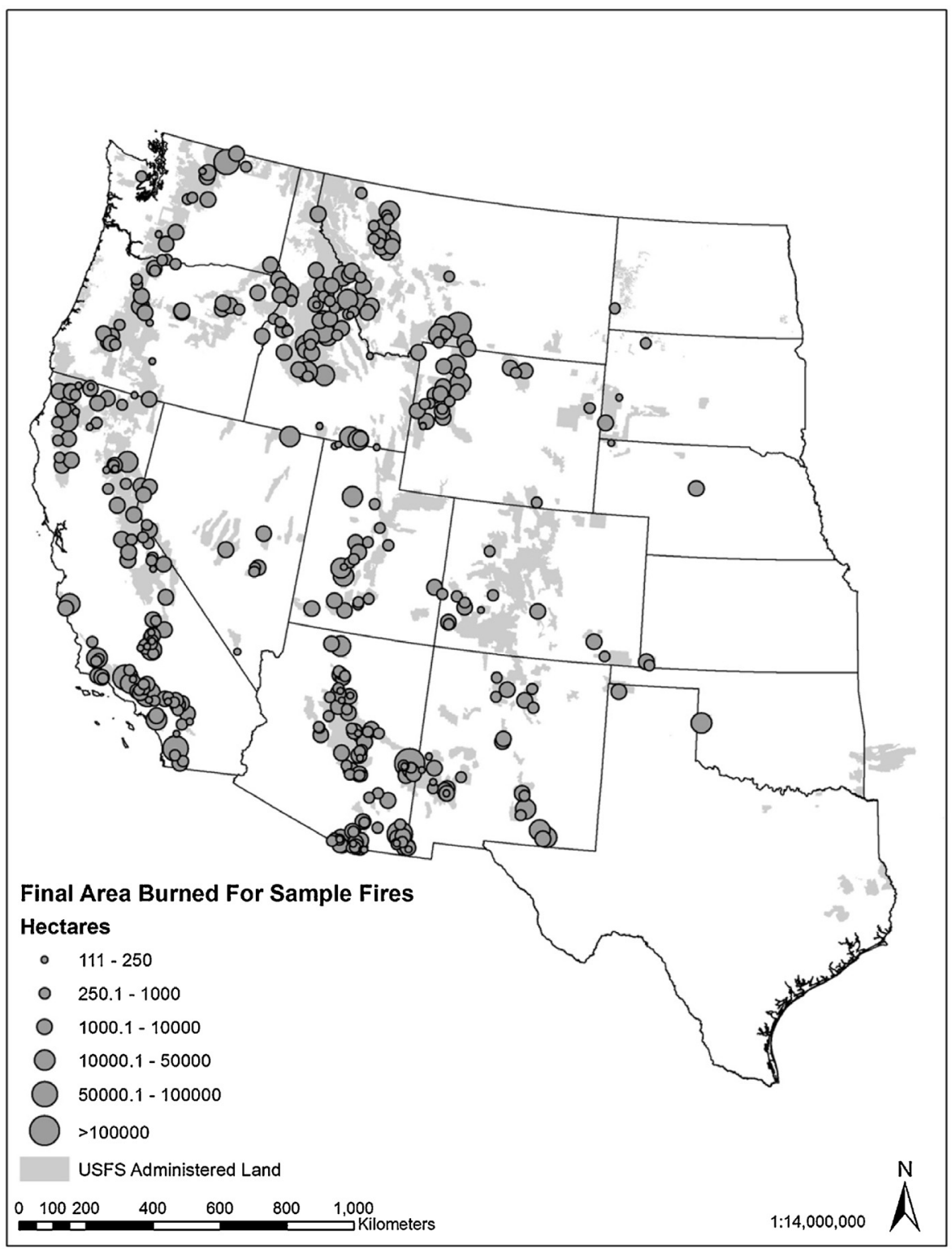

Fig. 2. Final burned area and geographic distribution of fires used in the regression sample (obs. $=406$ ).

As an empirical matter, we are not aware of any studies indicating that expenditures influence fire size, particularly for large fires that escape initial attack. The literature on fire expenditures is inconclusive about the exogeneity of fire size. For example, Gebert et al. (2007) cannot reject the hypothesis that fire size is exogenous. Gebert and Black (2012) find some evidence that fire size is endogenous, but with marginal confidence, while Donovan et al. (2011) more confidently reject exogeneity using a subset of the Gebert et al. (2007) data.

A possible explanation for the mixed results is that the objectives of engaging resources in fire suppression are not closely tied to minimizing the burned area of a fire. The general objective of fire 
Table 1

Variables used in spatially descriptive regression (Eq. (1)); obs. $=406$.

\begin{tabular}{|c|c|c|c|c|}
\hline Variable & Description & Source & Mean & Std. Dev. \\
\hline $\operatorname{lnexp}$ & $\begin{array}{l}\text { Natural log of total federal suppression } \\
\text { expenditures in constant } 2012 \$ \text { (Dep. Var.) }\end{array}$ & FFIS & 14.0 & 1.91 \\
\hline In_hectares & $\begin{array}{l}\text { Natural log of area (in hectares) within } \\
\text { final fire perimeter }\end{array}$ & NIFC FTP & 7.2 & 1.48 \\
\hline erc_max & $\begin{array}{l}\text { Maximum relative ERC percentile observed } \\
\text { during the fire within the final perimeter }\end{array}$ & $\begin{array}{l}\text { GIS calculation } \\
\text { of data from } \\
\text { Abatzoglou } \\
(2011)\end{array}$ & 92.8 & 12.9 \\
\hline erc_std & $\begin{array}{l}\text { Standard deviation of relative ERC } \\
\text { observed during the fire within the final } \\
\text { perimeter }\end{array}$ & $\begin{array}{l}\text { GIS calculation } \\
\text { of data from } \\
\text { Abatzoglou } \\
(2011)\end{array}$ & 14.2 & 11.3 \\
\hline In_elevation & $\begin{array}{l}\text { Natural log of the average elevation within } \\
\text { the final perimeter }\end{array}$ & LANDFIRE & 7.37 & .446 \\
\hline wild_burn & Burned within Wilderness area (binary) & WFDSS & .310 & .463 \\
\hline wild_share & $\begin{array}{l}\text { Share of final burned area within a } \\
\text { Wilderness area }\end{array}$ & WFDSS & .195 & .354 \\
\hline IRA_burn & $\begin{array}{l}\text { Burned within an Inventoried Roadless } \\
\text { Area (binary) }\end{array}$ & WFDSS & .488 & .500 \\
\hline IRA_share & Share of final burned area within an IRA & WFDSS & .226 & .330 \\
\hline SDA_burn & $\begin{array}{l}\text { Burned within other specially designated } \\
\text { area (binary) }\end{array}$ & WFDSS & .052 & .221 \\
\hline SDA_share & Share of final burned area within a SDA & WFDSS & .003 & .018 \\
\hline slope_0_20 & $\begin{array}{l}\text { Share of final burned area with slope less } \\
\text { than } 20 \% \text { (omitted reference category) }\end{array}$ & LANDFIRE & .371 & .304 \\
\hline slope 20_40 & $\begin{array}{l}\text { Share of final burned area with slope } \\
\text { between } 20 \% \text { and } 40 \%\end{array}$ & LANDFIRE & .281 & .149 \\
\hline slope_40_60 & $\begin{array}{l}\text { Share of final burned area with slope } \\
\text { between } 40 \% \text { and } 60 \%\end{array}$ & LANDFIRE & .213 & .149 \\
\hline slope_60_80 & $\begin{array}{l}\text { Share of final burned area with slope } \\
\text { between } 60 \% \text { and } 80 \%\end{array}$ & LANDFIRE & .108 & .125 \\
\hline slope_80_100 & $\begin{array}{l}\text { Share of final burned area with slope } \\
\text { greater than } 80 \%\end{array}$ & LANDFIRE & .025 & .053 \\
\hline usfs_share & $\begin{array}{l}\text { Share of final burned area in USFS } \\
\text { ownership }\end{array}$ & WFDSS & .815 & .297 \\
\hline doi_share & $\begin{array}{l}\text { Share of final burned area in Dept. of } \\
\text { Interior ownership }\end{array}$ & WFDSS & .041 & .133 \\
\hline grass_share & Share of final burned area with grass fuels & LANDFIRE & .474 & .309 \\
\hline brush_share & Share of final burned area with brush fuels & LANDFIRE & .127 & .183 \\
\hline timber_share & Share of final burned area with timber fuels & LANDFIRE & .377 & .299 \\
\hline slash_share & Share of final burned area with slash fuels & LANDFIRE & $1.5 \mathrm{e}-4$ & .002 \\
\hline In_house_val_in & $\begin{array}{l}\text { Natural log of housing value within the } \\
\text { final perimeter in constant } 2012 \$\end{array}$ & U.S. Census & .645 & 2.66 \\
\hline In_house_val_5 & $\begin{array}{l}\text { Natural log of housing value within } 5 \text { miles } \\
\text { of final perimeter in constant } 2012 \$\end{array}$ & U.S. Census & 4.70 & 5.89 \\
\hline In_house_val_10 & $\begin{array}{l}\text { Natural log of housing value between } 5 \text { and } \\
10 \text { miles from perimeter in constant } 2012 \$\end{array}$ & U.S. Census & 7.19 & 6.04 \\
\hline In_house_val_20 & $\begin{array}{l}\text { Natural log of housing value between } 10 \\
\text { and } 20 \text { miles from perimeter in constant } \\
2012 \$\end{array}$ & U.S. Census & 11.4 & 4.33 \\
\hline aspect_N_E & $\begin{array}{l}\text { Share of final burned area with North, } \\
\text { Northeast, or East aspect }\end{array}$ & LANDFIRE & .361 & .182 \\
\hline aspect_SE_SW & $\begin{array}{l}\text { Share of final burned area with Southeast, } \\
\text { South, or Southwest aspect }\end{array}$ & LANDFIRE & .396 & .183 \\
\hline aspect_W_NW & $\begin{array}{l}\text { Share of final burned area in West or } \\
\text { Northwest aspect (omitted reference } \\
\text { category) }\end{array}$ & LANDFIRE & .236 & .148 \\
\hline duration (raw) & $\begin{array}{l}\text { Fire duration measured from ignition date } \\
\text { to controlled/out date }\end{array}$ & NIFMID & 34.2 & 32.6 \\
\hline $\begin{array}{l}\text { duration } \\
\text { (top-code) }\end{array}$ & Fire duration top-coded at 90 days & NIFMID & 32.4 & 28.0 \\
\hline
\end{tabular}


Table 1 (Continued)

\begin{tabular}{lllll}
\hline Variable & Description & Source & Mean & Std. Dev. \\
\hline region1 & $\begin{array}{l}\text { Northern region identifier (binary, omitted } \\
\text { reference category) }\end{array}$ & NIFMID & .103 & .304 \\
region2 & Rocky Mountain region indicator (binary) & NIFMID & .071 & .257 \\
region3 & Southwest region indicator (binary) & NIFMID & .278 & .450 \\
region4 & Great Basin region indicator (binary) & NIFMID & .200 & .399 \\
region5 & California region indicator (binary) & NIFMID & .236 & .424 \\
region6 & Northwest region indicator (binary) & NIFMID & .111 & .316 \\
year06 & Year 2006 indicator (binary, omitted & NIFMID & .195 & .395 \\
& reference category) & NIFMID & .172 & .378 \\
year07 & Year 2007 indicator (binary) & NIFMID & .160 & .367 \\
year08 & Year 2008 indicator (binary) & NIFMID & .150 & .358 \\
year09 & Year 2009 indicator (binary) & NIFMID & .121 & .326 \\
year10 & Year 2010 indicator (binary) & NIFMID & .187 \\
year11 & Year 2011 indicator (binary) & .391 \\
\hline
\end{tabular}

Data sources: FFIS - Foundation Financial Information System, which is being replaced by the Financial Management Modernization Initiative (FMMI), available at http://info.fmmi.usda.gov/, accessed 9/3/2013. NIFMID - National Interagency Fire Management Integrated Database, maintained at the USDA National Information Technology Center in Kansas City, MO; NIFMID variables are self-reported by managers for each wildfire. NIFC FTP - available at ftp://ftp.nifc.gov/Incident_Specific_Data/, accessed 7/24/2013; WFDSS - Wildland Fire Decision Support System databases available at http://wfdss.usgs.gov/wfdss/WFDSS_Data_Downloads.shtml, accessed 7/24/2013; LANDFIRE - version 1.2.0 available at http://www.landfire.gov/lf_120.php, accessed 7/24/2013; LANDFIRE may not account for post-fire fuel transitions that occurred prior to 2010 and after the previous version of LANDFIRE (in 2008), although minimal changes in fuel shares are evident for the sample of fires used here.

management efforts may be to minimize economic losses (Hesseln et al., 2010), which may not be closely associated with fire size. Fire management efforts often involve significant expenditures on activities other than direct fire containment, such as point protection of valuable assets, monitoring, and post-fire rehabilitation. Further, the effects of suppression efforts on size may be ambiguous; burnout operations intended to reduce fire severity and/or slow fire spread may actually increase fire size, or decisions to limit suppression efforts at any given time (e.g., due to severe weather conditions) may result in fire growth but no effect on expenditures. Unfortunately data on when and where specific operational actions occur are seldom available outside of selected case studies (see Thompson et al., 2016 for an example where some detailed operational data is available).

Finally, expenditures are not likely the primary determinant of fire behavior and growth. Firerelated weather (Finney et al., 2009) and climatic conditions (Westerling et al., 2006) have been shown to have a strong influence on fire size. This is not to say that expenditures have no effect on fire outcomes, but managers may have relatively little influence over final fire size (see for example Calkin et al., 2014). A possible exception are wildfires that are managed for resource benefit where suppression activities are typically not directed at reducing the size of wildland fires, although this management approach is primarily limited to designated wilderness areas.

To account for potential endogeneity of fire size (and fire duration, discussed below), we estimate Eq. (1) using an instrumental variables (IV) method. Following the examples of Donovan et al. (2011) and Gebert and Black (2012), potential instruments for fire size include dummy variables indicating the year of ignition (year06-year11), the natural log of distance to the nearest city with a population of 250,000 (Indist250k), ignition during September, October, or November (SON), and an interaction between SON and a region 5 (California) dummy variable (SONxreg_5). The final IV specifications and tests are presented in the results section.

Geospatial data was calculated using a variety of GIS data layers overlaid with each of the fire perimeter polygons. GIS data are drawn from the Wildland Fire Decision Support System (WFDSS) and LANDFIRE. WFDSS includes GIS polygon data on land ownership and protected areas (such as Wilderness Areas and Inventoried Roadless Areas) drawn from public land surveys. LANDFIRE data is primarily based on remotely sensed data at a $30 \mathrm{~m}^{2}$ grid resolution. Fuel model categories are developed from field-referenced satellite imagery to classify vegetation into surface fuel categories. 
Slope, elevation, and aspect data in LANDFIRE are drawn from remotely sensed data in the National Elevation Dataset maintained by the U.S. Geological Survey.

Most geospatial variables are expressed in percentage terms, i.e., the percentage of the burned area of each fire that falls within a given category. Slope, jurisdictional ownership, vegetative fuel model, and aspect are all calculated in this way. In the regression model, one of the categories for each characteristic is omitted from the regression to avoid co-linearity (similar to omitting a category when including dummy variables).

Elevation (lnelev) is specified as a spatial mean, where the mean elevation within the perimeter is calculated for each fire. The elevation GIS layer is a raster dataset, meaning that $30 \times 30$ meter grid cells have unique elevation values. The lnelev variable uses the mean of elevation values for all grid cells that are within each fire's perimeter.

In contrast to other variables, energy release component (ERC) is characterized by temporal variation over the duration of a fire. ERC is a relative measure of fuel moisture and has been shown to be a good predictor of area burned in the western United States (Riley et al., 2013). Changing weather can result in spikes in ERC due to high temperatures and low humidity, or low ERC values corresponding to low temperatures and higher humidity or precipitation.

ERC data is drawn from a $4 \mathrm{~km}$ raster data set that identifies daily ERC values for each $4 \mathrm{~km}$ grid cell within each fire perimeter (Abatzoglou, 2013). These data are used to calculate two ERC variables included in the regressions: a maximum ERC value (erc_max), reflecting the highest relative ERC recorded within the final perimeter during the fire, and the standard deviation of relative ERC (erc_std) during the fire. The first measure is designed to account for cross-sectional differences in weather conditions that may be associated with extreme fire behavior (i.e., high relative ERC values). The second measure is designed to identify fires that may have experienced periods of time when conditions were less extreme and more amenable to suppression. The probability of containing wildfires increases during periods of quiescent weather (Finney et al., 2009); large variations in ERC may indicate fires where these periods occurred. Spatial variation in ERC was also explored using the raster data, but inspection of these data revealed relatively little spatial variation within most fire perimeters.

The values at risk of being affected by a fire are represented by the total value of housing within the final perimeter and within 5-, 10-, and 20-mile buffers of the perimeter. Housing value within the perimeter may indicate how suppression activities respond when homes are potentially affected by fire (though not necessarily damaged or destroyed); values outside the perimeter but relatively close to the perimeter may indicate how the threat of damage to valuable assets alters expenditures on suppression efforts whereas larger buffers may indicate increased socio political concerns regarding smoke production, potential loss of amenity values and economic use values on public lands.

Housing value is drawn from the 2000 Decennial Census data at the Census block level. ${ }^{8}$ Total housing value within a Census block is calculated by multiplying the average value by the number of homes in the block; for a given radius or perimeter buffer, the total housing value is the sum of total housing value for all blocks that intersect the radius or perimeter buffer. ${ }^{9}$ The variables used in the regression are the natural log of housing value within the perimeter (Inhousein), between the perimeter and the 5 -mile buffer (Inhouse $5=\ln$ (housing value 5 mi buffer - housing value perimeter)), between the 5and 10-mile buffers (Inhouse10 = In (housing value 10mi buffer - housing value $5 \mathrm{mi}$ buffer)) and between the 10- and 20-mile buffers (lnhouse20 = ln(housing value 20mi buffer - housing value 10mi buffer)).

\footnotetext{
8 Because our sample includes fires from 2006 to 2011, the housing value variables may suffer from some measurement error due to changes in value since 2000 in locations with rapid housing development, and changes in values resulting from the financial and housing market crisis in 2008. The former effect most likely results in an under-estimate of housing values, while the latter effect could result in either an over- or under-estimate of values depending on the year (pre- or post-2008 crises) and location of values being measured.

${ }^{9}$ Normalizing housing values by block area (e.g., average values per $\mathrm{km}^{2}$ ) is also a possible (thanks to an anonymous reviewer for pointing this out). The primary issue is that Census blocks vary in size, and in larger blocks there is additional uncertainty about exactly where relative to the fire perimeter or buffer the housing values are located. Normalizing would provide a measure of the average density of housing values in proximity to fires, but would not resolve measurement error associated with nonuniform distribution of values within blocks. To remain consistent with previous research we maintain the specification of total housing values (not normalized).
} 
Table 2

Tests of endogeneity of fire size and duration using 2SLS instrumental variables estimates of spatially descriptive data models.

\begin{tabular}{llll}
\hline & $\begin{array}{l}\text { Fire size endogenous, } \\
\text { duration endogenous } \\
(\text { d.f. }=2.35)\end{array}$ & $\begin{array}{l}\text { Fire size endogenous, } \\
\text { duration exogenous } \\
(\text { d.f. }=1.35)\end{array}$ & $\begin{array}{l}\text { Duration endogenous, } \\
\text { fire size exogenous } \\
\text { (d.f. }=1.35)\end{array}$ \\
\hline $\begin{array}{l}\text { F-Statistic } \\
\text { p-Value }\end{array}$ & 1.12 & 2.21 & 0.06 \\
\hline
\end{tabular}

Dependent variable is total suppression expenditures (lnexp). Instrumental variables: year of ignition dummy variables (year06-year11), the natural log of distance to the nearest city with a population of 250,000 (Indist 250k), ignition during September, October, or November $(S O N)$, and an interaction between SON and a region 5 (California) dummy variable (SONxreg_5).

Fire duration (duration) is measured from the ignition date to the date the fire was reported controlled or out. Duration was top-coded at 90 days (30 observations) to reduce potential measurement error due to fire records being updated well after an incident was completed (both the raw duration variable and the top-coded variable are described in Table 1). Following the example of Gebert and Black (2012) we investigated the possibility that duration may be endogenous. Similar to the reasoning with fire size as an endogenous variable, duration may be endogenous if expenditures affect the likelihood of fire containment and time required to control fire growth. Potential specifications tested included duration as a jointly endogenous variable with fire size, as an endogenous variable with fire size assumed to be exogenous, and as an instrumental variable when fire size is treated as endogenous.

Finally, categorical variables for USFS regions (1-6, with Region 1 as the base category) are included in both the spatially descriptive and ignition-point regressions. A robust result from previous studies is that fires in California (region 5) and the Pacific Northwest (region 6) tend to have higher expenditures per hectare than other regions.

\section{Results}

Tests for endogenous fire size and duration

Eq. (1) was estimated using two-stage least squares (2SLS) to test the null hypothesis that fire size and duration are exogenous (either jointly or independently). ${ }^{10}$ Total expenditures are significantly correlated with fire size $(\rho=0.56)$ and duration $(\rho=0.17)$, as are duration and fire size $(\rho=0.34)$.

Three initial specifications are tested: (1) fire size and duration as jointly endogenous variables, (2) fire size as an endogenous variable and duration as an exogenous variable included in the second-stage regression, and (3) duration as endogenous with fire size as an instrument included in the second-stage regression.

Endogeneity in each specification is tested using a robust Wald statistic that can be compared against critical values of the F-distribution (see Wooldridge, 2010, ch. 6). Table 2 presents the Fstatistics and $p$-values for the three 2SLS regression specifications. In each of these specifications we cannot reject the hypothesis that fire size and/or duration are exogenous at conventional confidence levels. However, when fire size is endogenous and duration is assumed exogenous, the $p$-value is not much larger than 0.10 .

Given the higher probability that fire size is endogenous (but duration is not), we also test a specification where fire size is endogenous but duration is used as an instrument for fire size (and excluded from the second-stage regression). This approach is similar to the specification presented in Gebert and Black (2012), and we similarly note that duration is not significantly related to expenditures per hectare when fire size is endogenous (specification 2). This alternate specification indicates that we can reject exogeneity for fire size with a higher degree of confidence ( $p=0.10$ compared with $p=0.15$ when duration is an included exogenous variable).

10 All regressions are implemented using STATA version 14. 
To summarize, we find no evidence that duration is endogenous, but a higher likelihood that fire size is endogenous. To avoid interpreting model coefficients that may suffer from endogeneity bias, we present and discuss results primarily for the specification with fire size as endogenous and duration included as an instrument.

\section{Parameter estimates}

The regression model in Eq. (1) generally performs well in identifying factors associated with total suppression expenditures. Table 3 reports the coefficient estimates for the OLS regression (fire size assumed exogenous) and the 2SLS regression (fire size is endogenous). Most independent variables have the expected sign and conform to previous suppression expenditure studies. However, the use of spatially descriptive data provides more nuanced insight about the relationship between expenditures and fire characteristics, particularly with respect to ERC (which indicates weather conditions

\section{Table 3}

Spatially descriptive data OLS and 2SLS regression parameter estimates for suppression expenditures (dep. var. $=$ lnexp, obs. $=406$ ).

\begin{tabular}{|c|c|c|c|c|}
\hline \multirow[t]{2}{*}{ Variable } & \multicolumn{2}{|c|}{ OLS - Fire size exog. } & \multicolumn{2}{|c|}{ 2SLS regression - Fire size endog. } \\
\hline & Coefficient & Standard error ${ }^{\mathrm{a}}$ & Coefficient & Standard error ${ }^{\mathrm{a}}$ \\
\hline In_hectares & $0.691^{* * *}$ & .041 & $.944^{* * *}$ & .175 \\
\hline erc_max & $.032^{* * *}$ & .007 & $.028^{* * *}$ & .008 \\
\hline erc_std & $-.018^{* *}$ & .007 & $-.025^{* * *}$ & .008 \\
\hline In_elevation & $.512^{* *}$ & .230 & $.518^{* *}$ & .225 \\
\hline wild_burn & -.141 & .335 & -.281 & .347 \\
\hline wild_share & $-1.00^{* *}$ & .457 & $-1.01^{* *}$ & .426 \\
\hline IRA_burn & $.399^{* *}$ & .170 & .082 & .265 \\
\hline IRA_share & -.343 & .289 & -.073 & .296 \\
\hline SDA_burn & .083 & .293 & -.213 & .356 \\
\hline SDA_share & 2.74 & 2.91 & 3.34 & 2.76 \\
\hline slope $20 \_40$ & .937 & .562 & $1.16^{*}$ & .611 \\
\hline slope_40_60 & .219 & .644 & .202 & .616 \\
\hline slope_60_80 & 1.24 & .920 & 1.21 & .888 \\
\hline slope_80_100 & .016 & 1.25 & .917 & 1.39 \\
\hline usfs_share & $1.19^{* * *}$ & .426 & $1.18^{* * *}$ & .410 \\
\hline doi_share & .724 & .502 & .484 & .501 \\
\hline brush_share & -.067 & .335 & .077 & .332 \\
\hline timber_share & $1.00^{* * *}$ & .287 & $1.14^{* * *}$ & .262 \\
\hline slash_share & 24.8 & 15.9 & $27.8^{*}$ & 15.1 \\
\hline ln_house_val_in & $-.045^{*}$ & .025 & $-.078^{* *}$ & .038 \\
\hline ln_house_val_5 & $.031^{* *}$ & .012 & $.026^{* *}$ & .012 \\
\hline In_house_val_10 & $.034^{* *}$ & .013 & $.030^{* *}$ & .013 \\
\hline In_house_val 20 & $.031^{* *}$ & .015 & $.038^{* *}$ & .015 \\
\hline aspect_N_E & .478 & .410 & .438 & .412 \\
\hline aspect_SE_SW & .427 & .581 & .586 & .573 \\
\hline region2 & -.140 & .262 & -.157 & .260 \\
\hline region3 & -.212 & .287 & -.218 & .292 \\
\hline region4 & .269 & .319 & .292 & .312 \\
\hline region5 & $1.62^{* * *}$ & .304 & $1.66^{* * *}$ & .298 \\
\hline region6 & $1.36^{* * *}$ & .363 & $1.38^{* * *}$ & .338 \\
\hline constant & -.719 & 1.91 & -2.20 & 1.70 \\
\hline$R^{2}$ & .669 & & .648 & \\
\hline Adj. $R^{2}$ & .643 & & .620 & \\
\hline RMSE & 1.143 & & 1.134 & \\
\hline
\end{tabular}

\footnotetext{
* Indicates significance at the $90 \%$ level.

** Indicates significance at the $95 \%$ level.

*** Indicates significance at the 99\% level.

a Standard errors adjusted for 36 year-region clusters.
} 
associated with fire growth), designated Wilderness Areas, and proximity of housing value. We primarily focus on the estimates from the 2SLS specification for discussion. ${ }^{11}$

Coefficient standard errors are estimated using the White heteroscedasticity-consistent estimator (Greene, 2003, ch. 10), with an adjustment for 36 region-year clusters (six regions across six years). The clusters assume that observations within a USFS region in a given year may be correlated, but are independent between regions and across years. This adjustment can aid in inference when characteristics are correlated geographically and temporally, as is likely the case with characteristics (e.g., ERC variables) that are related to climatic variations and weather events that occur on a regional scale. ${ }^{12}$

As expected, larger fires tend to have higher total suppression expenditures. The coefficient for fire size (ln_hectares) is positive and significant in both the OLS and 2SLS specifications. The results imply an elasticity for fire size less than one (i.e., a one percent change in size results in less than one percent change in expenditures), consistent with findings from the literature (e.g., Gebert et al., 2007) that expenditures per unit area decrease with increases in fire size. However, the 2SLS coefficient for fire size (ln_hectares) is about 50 percent larger in magnitude than the OLS regression. This suggests that ignoring the potential endogeneity of fire size would result in a downward-biased estimate of the relationship between size and expenditures.

Higher maximum ERC values (erc_max) are associated with higher expenditures, consistent with previous studies. This suggests that fire suppression activities are more difficult and costly when weather conditions favor extreme fire activity. However, greater variation in ERC values during the fire (i.e., higher erc_std values) is associated with lower expenditures. That is, fires that have periods of time when ERC values depart from their maximum may be easier to engage and less costly. This finding is consistent with periods of quiescent weather providing a containment opportunity for large fires (Finney et al., 2009).

The only specially designated lands that appear to be related to expenditures are Wilderness Areas. Expenditures are lower for fires with a larger share of area that burned in a Wilderness Area. This result is analogous to the finding in ignition-point models where fires with ignition points deeper within a Wilderness Area (i.e., with ignition points further from the wilderness boundary) are less costly. However, the results with spatially descriptive data suggest that even fires that ignite outside of a Wilderness Area will exhibit lower expenditures on average if a larger share of the fire burns inside the Wilderness boundary.

The use of final fire perimeters to identify the relative location of housing value potentially affected by fire reveals a discontinuous relationship with expenditures. Housing value within the final perimeter is negatively associated with expenditures (though marginally significantly in the OLS regression), but housing value outside fire perimeters is associated with higher suppression expenditures. The spatially descriptive housing value data appears to identify a relationship with expenditures based on location inside or outside the perimeter, which cannot be detected with the ignition-point data.

\section{Comparing model performance to ignition-point data}

An advantage of the spatially and temporally descriptive expenditure model is that it illustrates how expenditures differ with variation in landscape characteristics within or near the fire perimeter. However, the ignition-point models have proven capable of explaining a significant amount of variation in expenditures. Previous studies using spatially descriptive data do not address whether

\footnotetext{
11 Results are qualitatively similar under the alternative 2SLS model where both size and duration are endogenous. Confidence levels decrease for the coefficients for erc_std $(p=0.10)$, slash_share $(p=0.12)$, In_house_val_in $(p=0.08)$, In_house_val_5 (0.15), and ln_house_val_10 ( $p=0.09)$. Results available upon request.

12 The clustering adjustment does not have a large impact on most of the coefficient standard errors in this application, likely due to the fact that significant variation exists within region-year combinations on all of the independent variables. Small cluster size (on average 11 observations per cluster) does not appear to cause inference problems if we maintain the assumption that the number of clusters is suitable for an asymptotic approach (Wooldridge, 2010, ch. 20). For most coefficients the cluster-adjusted standard errors do not affect inference. Confidence levels decrease from the $1 \%$ to $5 \%$ level for the wild_share coefficient, from the $5 \%$ to $10 \%$ level for the slope $20 \_40$ coefficient, and increase to the $10 \%$ level for the slash_share coefficient. Results available upon request.
} 
the spatially descriptive model improves the explanatory power or predictive power over models estimated with ignition point data (Liang et al., 2008; Hand et al., 2014).

To examine the relative performance of the spatially descriptive model, a regression model is estimated using comparable ignition point data for the same sample of data used in the estimation sample above. Variables in the spatially descriptive model that describe how landscape characteristics vary within the final fire perimeter are replaced with variables that are recorded at the ignition point of each fire, consistent with previous expenditure modeling efforts (e.g., Gebert et al., 2007). ${ }^{13}$ For example, rather than specifying the share of the burned area in each of five slope classes in the spatially descriptive model, the ignition point model uses the slope recorded at the ignition point. Other variables, such as share of area in different fuel models, are replaced with binary variables indicating conditions at ignition. A summary of ignition point variables used in place of the spatially descriptive variables in the comparison regression are described in Table 4. Other variables are the same in both regressions, including fire size and regional dummy variables.

Although the model with ignition-point data is designed to be comparable with the model using spatially and temporally descriptive data, the underlying data are quite different and yield different interpretations. For example, the interpretation of the relationship between weather and fuel conditions and expenditures, described by ERC variables, is different in each model. The ignition-point model may be used to examine the relationship of expenditures with conditions at the start of the fire ("If a fire starts under cool and wet conditions, what is the expected effect on expenditures?"), whereas in the spatially descriptive model describes how expenditures are related to conditions over the course of the entire incident ("If weather conditions remain cool and wet during the fire, what is the expected effect on expenditures?" and, "If weather conditions change drastically during the incident, what is the expected effect on expenditures?").

The same regression methods are applied to the ignition point data, including estimating robust standard errors with adjustments for region-year clusters. As with the spatially descriptive model, we present results for models where fire size is included as exogenous and as an endogenous variable estimated with an instrumental variables regression. Table 5 reports the regression coefficients for the ignition point model. Overall the model performs reasonably well and yields conclusions about suppression expenditures that are qualitatively similar to the spatially descriptive model. The coefficient for fire size (ln_hectares) is positive and highly significant, although smaller in magnitude when compared with the spatially descriptive model when fire size is endogenous. Coefficients for the other ignition point variables are largely consistent with the coefficients for comparable variables in the spatially descriptive model.

The ignition point model also performs well in terms of goodness-of-fit, although not as well as the spatially descriptive model. The degrees of freedom-adjusted coefficient of determination (adjusted $R^{2}$ ) is slightly lower in the ignition point model, and the root mean squared error (RMSE) is larger. Using these goodness-of-fit measures, the results suggest that the spatially descriptive model provides a modest improvement in explanatory power and predictive ability.

Plots of the standardized residuals in each model against the standard normal distribution (Fig. 3) suggest that the model residuals approximate the shape of the normal distribution, although both models exhibit some skewedness and long left-hand tails. A Shapiro-Wilk test for normality of the standardized residuals rejects the hypothesis that the residuals are normally distributed for both models ( $p<0.01$ for both), indicating that there remain unobserved factors that could improve the fit and explanatory power of the models. ${ }^{14}$

Predictive ability is further investigated by comparing prediction errors between the two regressions. Predictions are of particular interest for using expenditure models to evaluate past performance

\footnotetext{
${ }^{13}$ Several variables from the National Interagency Fire Management Database (NIFMID) database used in the ignition-point model are reported by incident personnel during an incident. To investigate potential measurement error due to reporting errors, the ignition points for the sample were also processed using the GIS databases that provide data for the spatial model. Results for the geo-processed ignition-point models were qualitatively similar to the reported-data model, although model fit and prediction accuracy were slightly diminished with the geo-processed data models (results available upon request).

14 The test for normality of the residuals is based on the Royston (1982) extension of the Shapiro-Wilk test, implemented using the swilk command in STATA v.12.0.
} 


\section{Table 4}

Ignition-point variables used in comparison regression, with corresponding spatially descriptive variables; obs. $=406$.

\begin{tabular}{|c|c|c|c|c|c|}
\hline $\begin{array}{l}\text { Ignition-point } \\
\text { variable }\end{array}$ & Description & Source & Mean & Std. Dev. & $\begin{array}{l}\text { Corresponding } \\
\text { spatially descriptive } \\
\text { variable(s) }\end{array}$ \\
\hline cos_aspect & Cosine of aspect in radians & NIFMID & -.123 & .738 & $\begin{array}{l}\text { aspect_N_E, aspect } \\
\text { SE_SW, }\end{array}$ \\
\hline sin_aspect & Sine of aspect in radians & NIFMID & -.014 & .665 & aspect_W_NW \\
\hline grass & $\begin{array}{l}\text { Grass fuel model (binary, omitted } \\
\text { category) }\end{array}$ & NIFMID & .340 & .474 & grass_share \\
\hline brush & Brush fuel model (binary) & NIFMID & .027 & .163 & brush_share \\
\hline timber & Timber fuel model (binary) & NIFMID & .448 & .498 & timber_share \\
\hline slash & Slash fuel model (binary) & NIFMID & .049 & .217 & slash_share \\
\hline wild_ign & Wilderness area ignition (binary) & WFDSS & .195 & .396 & wild_burn \\
\hline ln_wild_dist & $\begin{array}{l}\text { Natural log of distance to } \\
\text { Wilderness area boundary, if } \\
\text { wild_ign }=1\end{array}$ & WFDSS & .188 & .483 & wild_share \\
\hline IRA_ign & $\begin{array}{l}\text { Inventoried Roadless Area ignition } \\
\text { (binary) }\end{array}$ & WFDSS & .197 & .398 & IRA_burn \\
\hline ln_IRA_dist & $\begin{array}{l}\text { Natural } \log \text { of distance to IRA } \\
\text { boundary, if } \text { ira_ign }=1\end{array}$ & WFDSS & .090 & .239 & IRA_share \\
\hline SDA_ign & $\begin{array}{l}\text { Other specially designated area } \\
\text { ignition (binary) }\end{array}$ & WFDSS & .037 & .189 & SDA_burn \\
\hline ln_SDA_dist & $\begin{array}{l}\text { Natural log of distance to other } \\
\text { SDA boundary, if other_ign }=1\end{array}$ & WFDSS & .022 & .146 & SDA_share \\
\hline usfs_own_ign & $\begin{array}{l}\text { USFS ownership at ignition } \\
\text { (binary) }\end{array}$ & WFDSS & .808 & .394 & usfs_share \\
\hline doi_own_ign & $\begin{array}{l}\text { Dept. of Interior ownership at } \\
\text { ignition (binary) }\end{array}$ & WFDSS & .071 & .258 & doi_share \\
\hline In_elevation_ign & Natural log of elevation in feet & NIFMID & 8.51 & .559 & In_elevation \\
\hline In_house_val_5ign & $\begin{array}{l}\text { Natural log of total housing value } \\
(000,000 \text { s } \$) \text { within } 5 \text { miles of } \\
\text { ignition }\end{array}$ & U.S. Census & 3.14 & 5.26 & $\begin{array}{l}\text { In_house_val_in, } \\
\text { ln_house_val_5 }\end{array}$ \\
\hline In_house_val_10ign & $\begin{array}{l}\text { Natural log of total housing value } \\
(000,000 \text { s } \$) \text { between } 5 \text { - and } \\
10 \text {-miles of ignition }\end{array}$ & U.S. Census & 6.50 & 5.03 & In_house_val_10 \\
\hline In_house_val_20ign & $\begin{array}{l}\text { Natural log of total housing value } \\
(000,000 \text { s } \$) \text { between } 10 \text { - and } \\
20 \text {-miles of ignition }\end{array}$ & U.S. Census & 10.7 & 4.92 & In_house_val_20 \\
\hline slope_ign & Percent slope at ignition & NIFMID & 38.2 & 25.8 & slope_0_20-slope_80_100 \\
\hline erc_ign & $\begin{array}{l}\text { Relative ERC percentile at ignition } \\
(0-100) \text {, calculated from reported } \\
\text { weather station historical data }\end{array}$ & NIFMID & 83.2 & 16.1 & erc_max, erc_std \\
\hline
\end{tabular}

Data sources: NIFMID - National Interagency Fire Management Integrated Database, maintained at the USDA National Information Technology Center in Kansas City, MO; NIFMID variables are self-reported by managers for each wildfire. WFDSS - Wildland Fire Decision Support System databases available at http://wfdss.usgs.gov/wfdss/WFDSS_Data_Downloads.shtml, accessed 7/24/2013; GIS calculations based on reported latitude and longitude ignition point from NIFMID. U.S. Census - Census block-level housing values. . ; GIS calculations based on reported latitude and longitude ignition point from NIFMID.

related to expenditures and examine the potential cost consequences of changes to landscape-level characteristics (e.g., fuel treatments; see Thompson et al., 2013c). Comparisons are reported for the instrumental variables (2SLS) models where fire size is endogenous. ${ }^{15}$

Comparisons of the spatially descriptive and ignition-point models are facilitated by constructing out-of-sample predictions based on a $k$-fold cross-validation method described by Varian (2014, p. 7). In the present application we randomly assign observations in the full dataset ( $n=406$ observations) to one of ten subsets of data (i.e., $k=10$ folds, $k=1, \ldots, 10, n_{k}=40$ or 41 , and $\sum_{k} n_{k}=n$ ). The regressions with spatially descriptive data and ignition-point data are estimated 10 times, each time omitting

\footnotetext{
15 Model performance results are qualitatively similar if the OLS models are used for the comparisons. The 2SLS models yield a slightly more conservative estimate of the differences between the models.
} 
Table 5

Ignition-point data OLS and 2SLS regression parameter estimates for suppression expenditures (dep. var. $=$ lnexp, obs. $=406$ ).

\begin{tabular}{|c|c|c|c|c|}
\hline \multirow[b]{2}{*}{ Variable } & \multicolumn{2}{|c|}{ OLS - Fire size exog. } & \multicolumn{2}{|c|}{ 2SLS regression - Fire size endog. } \\
\hline & Coefficient & Standard error ${ }^{\mathrm{a}}$ & Coefficient & Standard error ${ }^{\mathrm{a}}$ \\
\hline In_hectares & $.698^{* * *}$ & .033 & $.767^{* * *}$ & .082 \\
\hline cos_aspect & -.080 & .097 & -.073 & .092 \\
\hline sin_aspect & .066 & .074 & .066 & .072 \\
\hline brush & .709 & .435 & .638 & .397 \\
\hline timber & $.660^{* * *}$ & .130 & $.633^{* * *}$ & .133 \\
\hline slash & $.456^{* *}$ & .204 & $.449^{* *}$ & .194 \\
\hline wild_ign & .222 & .361 & .196 & .348 \\
\hline In_wild_dist & $-.888^{* * *}$ & .274 & $-.882^{* * *}$ & .266 \\
\hline IRA_ign & .239 & .204 & .241 & .204 \\
\hline ln_IRA_dist & -.237 & .412 & -.225 & .409 \\
\hline SDA_ign & $1.07^{* *}$ & .405 & $1.04^{* * *}$ & .393 \\
\hline ln_SDA_dist & $-1.48^{* *}$ & .682 & $-1.45^{* *}$ & .650 \\
\hline usfs_own_ign & $.663^{* *}$ & .273 & $.689^{* * *}$ & .264 \\
\hline doi_own_ign & .389 & .275 & .402 & .271 \\
\hline In_elevation_ign & $.343^{*}$ & .195 & $.342^{*}$ & .179 \\
\hline ln_house_val_5ign & .013 & .015 & .013 & .015 \\
\hline ln_house_val_10ign & $.025^{* *}$ & .010 & $.025^{* *}$ & .010 \\
\hline ln_house_val_20ign & $.022^{*}$ & .013 & $.024^{* *}$ & .012 \\
\hline slope_ign & $.005^{* *}$ & .002 & $.005^{* *}$ & .002 \\
\hline erc_ign & $.027^{* * *}$ & .013 & $.026^{* * *}$ & .005 \\
\hline region2 & -.009 & .002 & .040 & .260 \\
\hline region3 & .173 & .304 & .197 & .302 \\
\hline region4 & $.451^{*}$ & .265 & $.477^{*}$ & .258 \\
\hline region5 & $1.95^{* * *}$ & .287 & $1.96^{* * *}$ & .281 \\
\hline region6 & $1.24^{* * * *}$ & .366 & $1.26^{* * *}$ & .341 \\
\hline constant & 1.64 & 1.89 & 1.15 & 1.54 \\
\hline$R^{2}$ & .636 & & .634 & \\
\hline Adj. $R^{2}$ & .613 & & .610 & \\
\hline RMSE & 1.191 & & 1.156 & \\
\hline
\end{tabular}

${ }^{*}$ Indicates significance at the $90 \%$ level.

** Indicates significance at the $95 \%$ level.

*** Indicates significance at the $99 \%$ level.

a Standard errors adjusted for 36 year-region clusters.

observations in one of the data subsets. Each iteration of the regression is used to construct out-ofsample predictions for the subset of observations not included in the iteration estimation sample. Thus, all observations will be included in $k-1$ regressions, and have an out-of-sample prediction from one regression iteration. ${ }^{16}$

For each observation, a predicted value of the dependent variable is generated for both the spatially descriptive and ignition point model, which also defines the prediction errors for the models. Standardized prediction errors for observation $j$ are expressed in standard deviation units, or $\widehat{\varepsilon_{j}}=\mid\left(y_{j}-\widehat{y_{j}}\right) / s_{j}$, where $s_{j}=\sqrt{x_{j} V x_{j}^{\prime}}$ and $V$ is the model variance-covariance matrix from the regression that omits observation $j$. This allows for comparisons of the relative size of residuals between models and evaluations of each model's ability to predict expenditures within acceptable confidence bounds.

Fig. 4 displays the distribution of standardized out-of-sample prediction errors for each model. Results are presented for the 2SLS instrumental variables specification where fire size is endogenous and duration is an instrument excluded from the second-stage regression. Overall the spatially descriptive model does a better job of generating out-of-sample predictions that are relatively closer to actual observations. The largest improvement in performance appears to be for those observations

\footnotetext{
16 The out-of-sample predictions are robust to alternative values of $\mathrm{k}$ and random assignment to each of the data subsets. For example, a jackknife method, where $k=n$ and the regression is iterated $\mathrm{n}$ times omitting a single observation yielded out-of-sample predictions that are similar to the $k=10$ results.
} 

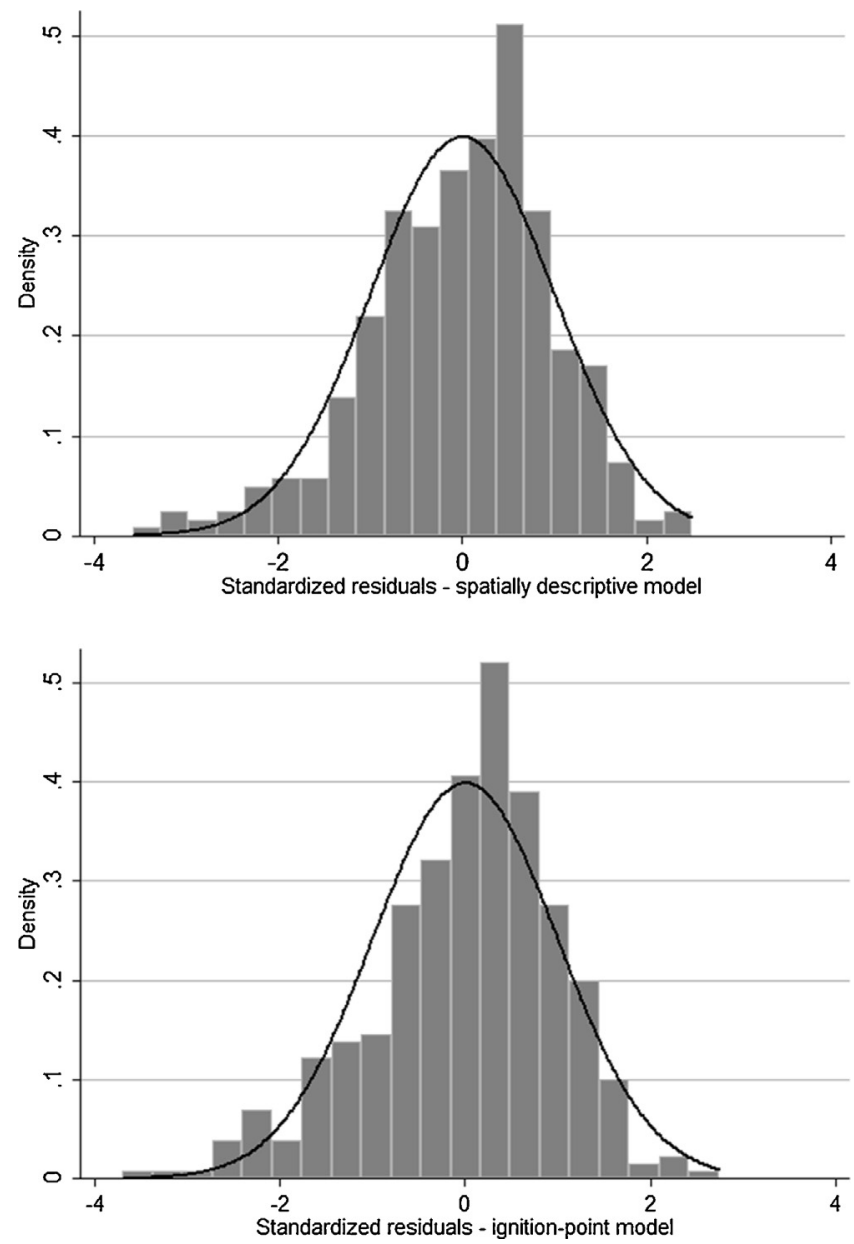

Fig. 3. Histograms of standardized model residuals for the spatially descriptive model (top panel) and ignition-point model (bottom panel).

where prediction errors are large ( $>4$ standard deviations). The spatially descriptive model reduces the number of observations with standardized prediction errors greater than four standard deviations by about $27 \%$.

Although the spatially descriptive model overall offers better predictions of expenditures, it cannot be said that the model is strictly a better predictive model across the entire sample. For a share of the sample, predictions are worse using the spatially descriptive model. Panel A of Table 6 summarizes the difference in the absolute value of the standardized prediction error for the spatial model compared with the ignition point model (i.e., $\Delta \epsilon_{j}=\widehat{\epsilon_{j}^{s}}-\widehat{\epsilon_{j}^{i}}$ where $\widehat{\epsilon_{j}^{s}}$ and $\widehat{\epsilon_{j}^{i}}$ represent the standardized prediction errors for the spatial data and ignition-point models, respectively). About $10 \%$ of the sample saw prediction errors that were larger in the spatial model by more than two standard deviations; for these observations, the model is performing significantly worse than the ignition point model, although it is not clear from observable characteristics why these observations perform worse under the spatial model.

About $23 \%$ of the sample shows improvements in prediction errors by at least two standard deviations, and overall more observations show smaller prediction errors in the spatially descriptive model 


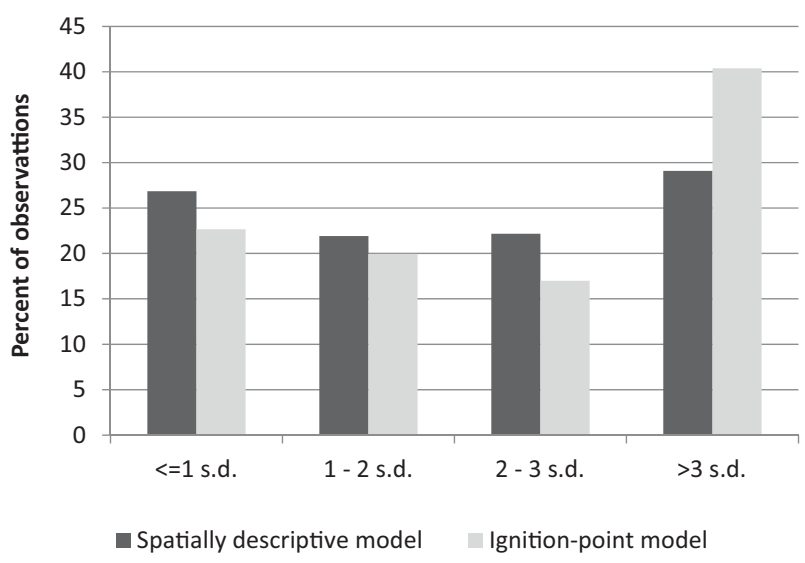

Fig. 4. Distribution of standardized (absolute value) residuals from out-of-sample predictions for the spatially descriptive and ignition-point models (obs. $=406$ ).

than those that show greater errors. On average, prediction errors were reduced in the spatially descriptive model by about 0.57 standard deviations (panel B, Table 6 ).

\section{Comparing expenditure predictions to the ignition-point model}

The spatially descriptive model may be useful for evaluating the cost consequences of management actions or other events that could change fire behavior and spread. To illustrate how the two models differ in expenditure predictions, we develop examples of hypothetical fire scenarios based on three actual fires in the estimation sample. Of particular interest is how the two models predict differences in expenditures when the ignition point remains constant but fire behavior and spread are altered. For example, fuel treatments might result in smaller fires on average (e.g., in a pre- and post-treatment landscape described by Thompson et al., 2013c), or changes in suppression strategies or weather events may allow fire growth in some areas (e.g., Wilderness) and not others (e.g., Wildland-Urban Interface areas).

\section{Table 6}

Comparison of out-of-sample prediction errors between the spatially descriptive model and the ignition-point model - 2SLS instrumental variables specification.

\begin{tabular}{|c|c|c|}
\hline Difference category & Frequency & Percent \\
\hline \multicolumn{3}{|c|}{$\begin{array}{l}\text { a. Distribution of differences in standardized prediction errors ( } \Delta \epsilon_{j} \text {; negative values indicate improved predictions with spatia } \\
\text { model) }\end{array}$} \\
\hline$\Delta \in>3$ s.d. & 14 & 3.4 \\
\hline 2 s.d. $<\Delta \in<3$ s.d. & 26 & 6.4 \\
\hline 1 s.d. $<\Delta \in<2$ s.d. & 51 & 12.6 \\
\hline-1 s.d. $<\Delta \in<1$ s.d. & 145 & 35.7 \\
\hline-2 s.d. $<\Delta \in<-1$ s.d. & 79 & 19.5 \\
\hline-3 s.d. $<\Delta \in<-2$ s.d. & 50 & 12.3 \\
\hline$\Delta \in<-3$ s.d. & 41 & 10.1 \\
\hline All obs. & 406 & 100 \\
\hline \multicolumn{3}{|c|}{ b. Change in standardized prediction errors ( $\Delta \epsilon ;$ negative values indicate improved predictions with spatial model) } \\
\hline Mean & -0.569 & \\
\hline Std. dev. & 2.27 & \\
\hline
\end{tabular}



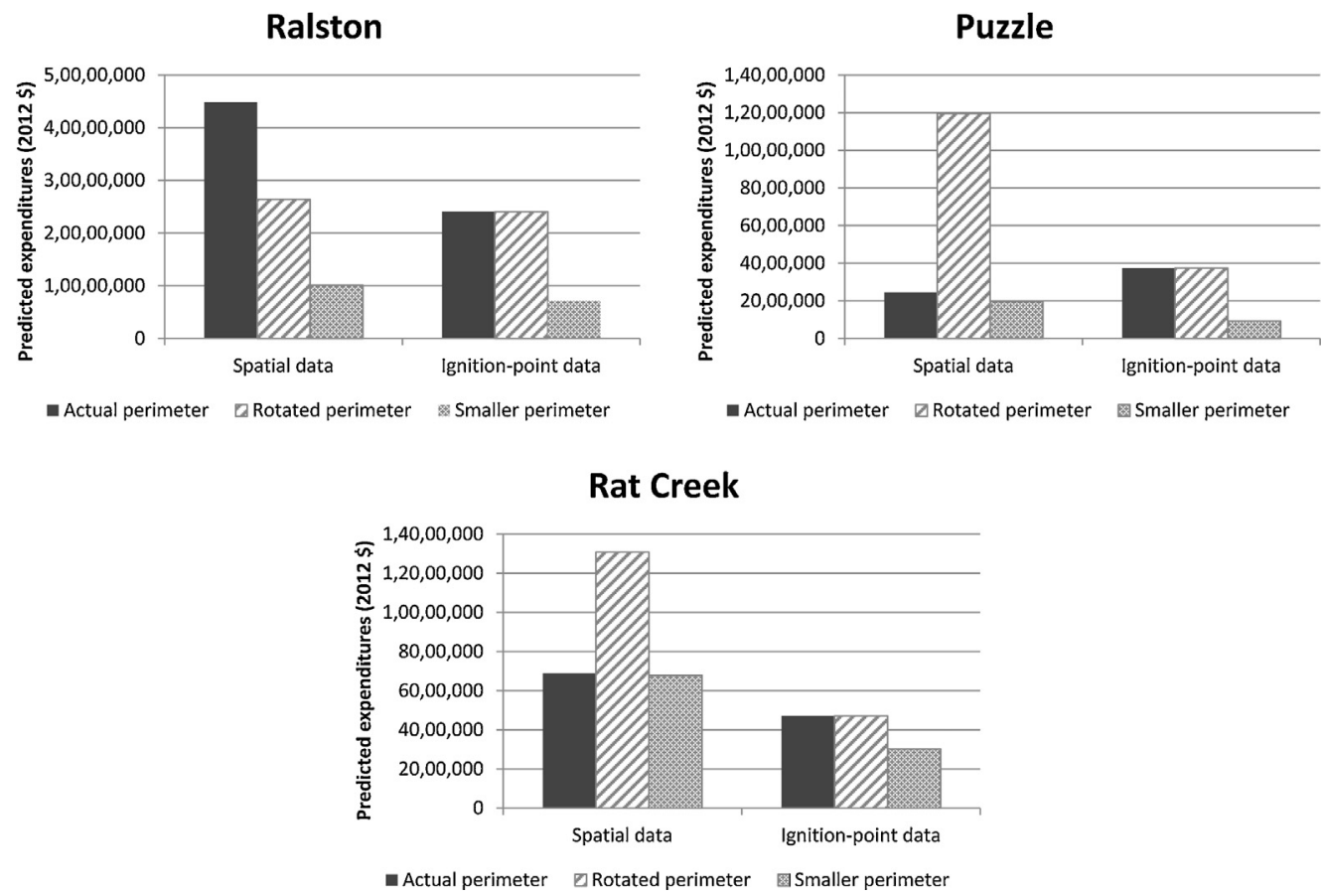

Fig. 5. Predicted expenditures for three fires with hypothetical counter-factual fire perimeters, by model.

For the three example fires from the dataset, we construct two separate hypothetical scenarios and examine expenditure predictions using both models for each scenario. ${ }^{17}$ In the first scenario we simulate fires that spread over a different area from the actual burned area. Holding constant the ignition point, perimeter shape, and final fire size, perimeters are rotated clockwise on the landscape by $45^{\circ}$. By definition the expenditure predictions from the ignition-point model will not change from the actual fire to the simulated fire. Predictions from the spatially descriptive model will change based on the characteristics of the new simulated area burned.

The second scenario holds constant the ignition point, perimeter shape, and orientation of the perimeter, but reduces fire size by shrinking the final perimeter by $1 \mathrm{~km}$ to the centroid. Predicted expenditures from the ignition-point model will be monotonically lower due to reduced final fire size. The predictions from the spatially descriptive model will be lower primarily due to smaller size, but the effects of other variables on predicted expenditures will depend on the characteristics of the smaller area within the final perimeter.

Fig. 5 displays predicted expenditures from both models for the three fires under actual conditions, the rotated perimeter, and the smaller perimeter. The examples highlight two points. First, even when size is held constant, differences in where a fire burns can have potentially large cost consequences that the ignition point model does not detect. Second, with the spatially descriptive model the effect of size on expenditures is not monotonic; the size effect may be outweighed by other changes in a fire's characteristics for some fires (the Puzzle and Rat Creek fires in this example) but not others. Capturing these effects may be important when predicting suppression expenditures in areas where

\footnotetext{
17 The three selected fires - Ralston (Tahoe NF, Sept. 5, 2006), Puzzle (Willamette NF, Aug. 19, 2006), and Rat Creek (BeaverheadDeerlodge NF, Aug. 9, 2007) - were selected to represent a range of locations and conditions. For ease of illustration, the ERC variables in the spatially descriptive model are held constant and not recalculated for the new fire perimeters. Values of the changed variables for each fire available from the authors upon request.
} 
small differences in fire behavior and spread can result in large changes to the characteristics of the burned area.

\section{Conclusion}

Wildfires typically involve complex landscape and geographic conditions that exhibit heterogeneity over the course of a given incident. The empirical results reported here suggest that the way that managers respond to heterogeneous conditions over time is an important factor that determines management expenditures on a wildfire incident. Previous research on the relationships between fire characteristics and expenditures has almost exclusively relied on data describing conditions at the time and point of ignition (Gebert et al., 2007; Donovan et al., 2011; Yoder and Gebert, 2012). The contribution of this study is to demonstrate the usefulness of spatially and temporally descriptive data to understanding suppression expenditures and the development of decision support tools.

Regression models that incorporate heterogeneous spatial and temporal descriptions of fire conditions explained variations in expenditures modestly better than comparable models based on data collected at a fire's ignition point and time. Out-of-sample predictions of expenditures were also improved with the spatially descriptive models. The results are consistent with heterogeneity introducing measurement error in the independent variables of expenditure regressions that is not accounted for in models using ignition-point conditions; accounting for this measurement error with spatially and temporally descriptive data appears to reduce model error variance.

Improved spatially and temporally descriptive data does not yield any broad changes in our understanding of the factors related to wildfire management expenditures, although some more nuanced interpretation of those factors is available. For example, we demonstrate for the first time the influence of temporal variation in fire weather on expenditures. Although higher energy release component values (ERC, indicating conditions conducive to extreme fire behavior) are associated with greater expenditures in both models, greater temporal variations in ERC are associated with lower expenditures.

Conclusions about the role of specially designated lands also provide novel interpretations. In the spatially descriptive model, fires with a greater share of burned area in Wilderness Areas tend to be less expensive, whereas in the ignition-point model fires that ignite further within Wilderness Areas are less expensive. Results highlight the potential importance of protection designations, fire management objectives, and land ownership, and indicate an opportunity to consider fire management plans and the degree of flexibility afforded fire to managers (Thompson et al., 2013b).

Finally, spatially descriptive data indicates that the location of assets threatened by fire (primarily housing value) relative to the burned area is important for expenditures; ignition-point data could not identify this effect. The negative association between housing value within a fire's burned area and expenditures could be due to fires with short periods of rapid fire growth resulting in homes being located within the perimeter but relatively little opportunity to incur suppression expenditures. It is also possible that the housing value variables are associated with the effect of socio-political pressure on expenditures identified by Donovan et al. (2011). The negative coefficient for housing value within the perimeter and larger positive coefficients at distances further from the perimeter may result if measures of socio-political pressure (i.e., newspaper coverage and senior political representation) are positively correlated with housing values further from the perimeter. However, these potential explanations are left for future research.

The primary value of these results may be the ability to leverage spatially explicit data generated by fire simulation models. A spatially descriptive expenditure model could be used to estimate the effect of fuel treatments on future suppression expenditures; as demonstrated with the hypothetical examples in the previous section, the spatially descriptive model captures the effects on expenditures of changing conditions independently of changes in size. Current research uses an ignition-point model to estimate expenditures for simulated fires in a pre- and post-treatment landscape (Thompson et al., 2013c), and cannot account for differences in the composition of fuels, ownership, and land protection between similarly sized fires. 
The spatially descriptive model sets the stage for a number of expanded analyses with additional information. Empirical research has established that past fire scars can exert controls on the size and severity of wildfires (Teske et al., 2012; Parks et al., 2013), and modeling efforts have suggested vast differences in fire outcomes had more fire been allowed to burn on the landscape (Miller et al., 2012; Houtman et al., 2013). Future uses of the new expenditure model could analyze the influence of past wildfire activity on expected suppression costs.

Future research may also be useful for integrating spatially descriptive expenditure models in decision support tools, such as the Wildland Fire Decision Support System (WFDSS). WFDSS makes extensive use of fire simulation outputs, including spatial representations of where a fire is likely to burn. Although beyond the scope of this study, the spatially descriptive expenditure model could provide a probability weighted expected expenditure map based on a set of underlying fire simulations. A geospatial representation of expected suppression expenditures has been developed with an ignition-point model (Preisler et al., 2011), although no attempt has yet been made to integrate this representation within decision support tools.

Two limitations of the data are evident. First, the geospatial data for some characteristics is relatively coarse and can prevent finer-scale inferences of the spatial relationships between landscape heterogeneity and expenditures. For example, fuel model variables are aggregated into broad categories, which may be too coarse to enable comparisons of expenditures based on changing fuel composition within the same broad fuel model. Second, the data represent a snapshot of the entire incident based on the final perimeter and aggregate expenditures, and do not describe how the progression of fire over a heterogeneous landscape relates to expenditures or specific suppression activities (e.g., the time of initial intervention relative to fire growth). Although data is available for many fires on how the perimeter progresses during the incident, corresponding financial data and detailed operational information is not typically available.

A related limitation of the analysis is that the existing cross-section data, even when incorporating spatially descriptive information, does not allow for inferences about how managers respond to heterogeneity by changing strategies and decisions during an incident. The approach in this paper is to use measures of goodness-of-fit and prediction accuracy as evidence that spatially descriptive data reduces measurement error problems in the cross-sectional data. The evidence supports this hypothesis, although further research is required to more completely describe how heterogeneity affects management decisions and strategy choices.

Finally, we note that a significant portion of variation in suppression expenditures remains unexplained, and several variables that are hypothesized to be related to expenditures are insignificant (e.g., slope and aspect). This suggests that other factors that may be unrelated to geographic and landscape characteristics play a role in determining expenditures. Fire managers respond to and face a variety of human factors that likely exhibit strong influences on decisions and expenditures, irrespective of spatial or temporal heterogeneity (Thompson, 2014). These include socio-political factors (Donovan et al., 2011), institutional and community pressures (Calkin et al., 2013), and risk preferences and decision biases (Wilson et al., 2011; Wibbenmeyer et al., 2013). Understanding whether or not expenditures are related to heterogeneous landscape and geographic characteristics may indicate the ability that managers have to respond to changing conditions during an incident. However, the considerable unexplained variance suggests a need to further examine sociopolitical influence and managerial factors to improve the explanatory power of these and other models.

\section{References}

Abatzoglou, J.T., 2013. Development of gridded surface meteorological data for ecological applications and modelling. Int. J. Climatol. 33 (1), 121-131.

Ager, A.A., Vaillant, N.M., McMahan, A., 2013. Restoration of fire in managed forests: a model to prioritize landscapes and analyze tradeoffs. Ecosphere 4 (2), 19 pp.

Calkin, D.E., Gebert, K.M., Jones, G., Neilson, R.P., 2005. Forest service large fire area burned and suppression expenditure trends 1970-2002. J. For. 103 (4), 179-183.

Calkin, D.E., Rieck, J.D., Hyde, K.D., Kaiden, J.D., 2011. Built structure identification in wildland fire decision support. Int. J. Wildland Fire 20 (1), 78-90. 
Calkin, D.E., Venn, T.J., Wibbenmeyer, M.J., Thompson, M.P., 2013. Estimating U.S. Federal wildland fire managers' preferences toward competing strategic suppression objectives. IJWF 22 (2), 212-222.

Calkin, D.E., Hand, M.S., Katuwal, H., Thompson, M.P., 2014. The effectiveness of suppression resources in large fire management in the US. In: Domingo Xavier Viegas (Ed.), Advances in Fire Research., http://dx.doi.org/10.14195/978-989-26-0884-6.

Canton-Thompson, J., Gebert, K.M., Thompson, B., Jones, G., Calkin, D., Donovan, G., 2008. External human factors in incident management team decisionmaking and their effect on large fire suppression expenditures. J. For. 106 (8), 416-424.

Donovan, G.H., Prestemon, J.P., Gebert, K.M., 2011. The effect of newspaper coverage and political pressure on wildfire suppression costs. Soc. Nat. Resour. 24 (8), 785-798.

Finney, M.A., Grenfell, I.C., McHugh, C.W., 2009. Modeling containment of large wildfires using generalized linear mixed model analysis. For. Sci. 55 (3), 249-255.

Fried, J.S., Gilless, J.K., Spero, J., 2006. Analysing initial attack on wildland fires using stochastic simulation. Int. J. Wildland Fire $15(1), 137-146$.

GAO, 2009. Wildland fire management: Federal agencies have taken important steps forward, but additional action is needed to address remaining challenges. Testimony before the Committee on Energy and Natural Resources, U.S., Senate, GAO-09906T, Available from: http://www.gao.gov/products/GAO-09-906T (accessed 03.06.14).

Gebert, K.M., Black, A.E., 2012. Effect of suppression strategies on federal wildland fire expenditures. J. For. 110 (2), 65-73.

Gebert, K.M., Calkin, D.E., Yoder, J., 2007. Estimating suppression expenditures for individual large wildland fires. Western J. Appl. For. 22 (3), 188-196.

Greene, W.H., 2003. Econometric Analysis, vol. 1., 5th ed. Prentice Hall, Upper Saddle River, NJ.

Gude, P.H., Jones, K., Rasker, R., Greenwood, M.C., 2013. Evidence for the effect of homes on wildfire suppression costs. IJWF 22 (4), 537-548

Hand, M.S., Gebert, K.M., Liang, J., Calkin, D.E., Thompson, M.P., Zhou, M., 2014. Economics of Wildfire Management: The Development and Application of Suppression Expenditure Models. Springer Briefs in Fire Springer, New York.

Hesseln, H., Amacher, G.S., Deskins, A., 2010. Economic analysis of geospatial technologies for wildfire suppression. Int. J. Wildland Fire 19 (4), 468-477.

Houtman, R.M., Montgomergy, C.A., Gagnon, A.R., Calkin, D.E., Dietterich, T.G., McGregor, S., Crowley, M., 2013. Allowing a wildfire to burn: estimating the effect on future fire suppression costs. IJWF 22 (7), 871-882.

Liang, J., Calkin, D.E., Gebert, K.M., Venn, T.J., Silverstein, R.P., 2008. Factors influencing large wildland fire suppression expenditures. IJWF 17 (5), 650-659.

Miller, J.D., Skinner, C.N., Safford, H.D., Knapp, E.E., Ramirez, C.M., 2012. Trends and causes of severity, size, and number of fires in northwestern California, USA. Ecol. Appl. 22 (1), 184-203.

Noonan-Wright, E., Opperman, T.S., Finney, M.A., Zimmerman, T., Seli, R.C., Elenze, L.M., Calkin, D.E., Fiedler, J.R., 2011. Developing the U.S. wildland fire decision support system. J. Combust., Article ID 168473, 14 pp.

Parks, G.M., 1964. Development and application of a model for suppression of forest fires. Manag. Sci. 10 (4), $760-766$.

Parks, S.A., Miller, C., Nelson, C.R., Holden, Z.A., 2013. Previous fires moderate burn severity of subsequent wildland fires in two large western US wilderness areas. Ecosystems 17 (1), 29-42.

Preisler, H.K., Westerling, A.L., Gebert, K.M., Munoz-Arriola, F., Holmes, T.P., 2011. Spatially explicit forecasts of large wildland fire probability and suppression costs for California. IJWF 20 (4), 508-517.

Riley, K.L., Abatzoglou, J.T., Grenfell, I.C., Klene, A.E., Heinsch, F.A., 2013. The relationship of large fire occurrence with drought and fire danger indices in the western USA, 1984-2008: the role of temporal scale. IJWF 22 (7), 894-909.

Royston, J.P., 1982. An extension of Shapiro and Wilk's W test for normality to large samples. J. R. Stat. Soc. Ser. C (Appl. Stat.) $31(2), 115-124$.

Scott, J.H., Helmbrecht, D.J., Parks, S.A., Miller, C., 2012a. Quantifying the threat of unsuppressed wildfires reaching the adjacent wildland-urban interface on the Bridger-Teton National Forest, Wyoming. Fire Ecol. 8 (2), 125-142.

Scott, J., Helmbrecht, D., Thompson, M.P., Calkin, D.E., Marcille, K., 2012b. Probabilistic assessment of wildfire hazard and municipal watershed exposure. Nat. Hazards 64 (1), 707-728.

Scott, J.H., Thompson, M.P., Calkin, D.E., 2013. A wildfire risk assessment framework for land and resource management. Gen. Tech. Rep. RMRS-GTR-315. U.S. Dept. of Agriculture, Forest Service, Rocky Mountain Research Station, Ft. Collins, CO, 83 pp.

Taylor, M.H., Rollins, K., Kobayashi, M., Tausch, R.J., 2013. The economics of fuel management: wildfire, invasive plants, and the dynamics of sagebrush rangelands in the western United States. J. Environ. Manag. 126, 157-173.

Teske, C.C., Seielstad, C.A., Queen, L.P., 2012. Characterizing fire-on-fire interactions in three large wilderness areas. Fire Ecol. 8 (2), 82-106.

Thompson, M.P., 2013. Modeling wildfire incident complexity dynamics. PLOS ONE 8 (5), 10 pp.

Thompson, M.P., 2014. Social, institutional, and psychological factors affecting wildfire incident decision making. Soc. Nat. Resour. 27 (6), 636-644.

Thompson, M.P., Freeborn, P., Rieck, J., Calkin, D., Gilbertson-Day, J., Cochrane, M., Hand, M., 2016. Quantifying the influence of previously burned areas on suppression effectiveness and avoided exposure: a case study of the Las Conchas fire. Int. J. Wildland Fire 25 (2), 167-181.

Thompson, M.P., Scott, J., Helmbrecht, D., Calkin, D.E., 2013a. Integrated wildfire risk assessment: framework development and application on the Lewis and Clark National Forest in Montana, USA. Integr. Environ. Assess. Manag. 9 (2), 329-342.

Thompson, M.P., Stonesifer, C.S., Seli, R.C., Hovorka, M., 2013b. Developing standardized strategic response categories for fire management units. Fire Manag. Today 73 (1), 18-24.

Thompson, M.P., Vaillant, N.M., Haas, J.R., Gebert, K.M., Stockmann, K.D., 2013c. Quantifying the potential impacts of fuel treatments on wildfire suppression costs. J. For. 111 (1), 49-58.

USDA OIG, 2006. Audit report: Forest Service large fire suppression costs. United States Department of Agriculture, Office of Inspector General, Report No. 08601-44-SF, Available from: http://www.usda.gov/oig/rptsauditsfs.htm (accessed 03.06.14).

Varian, H.R., 2014. Big data: new tricks for econometrics. J. Econ. Perspect. 28 (2), 3-28.

Westerling, A.L., Hidalgo, H.G., Cayan, D.R., Swetnam, T.W., 2006. Warming and earlier spring increase western U.S. forest wildfire activity. Science 313 (5789), 940-943. 
Wibbenmeyer, M.J., Hand, M.S., Calkin, D.E., Venn, T.J., Thompson, M.P., 2013. Risk preferences in strategic wildfire decision making: a choice experiment with U.S. wildfire managers. Risk Anal. 33 (6), 1021-1037.

Wilson, R.S., Winter, P.L., Maguire, L.A., Ascher, T., 2011. Managing wildfire events: risk-based decision making among a group of federal fire managers. Risk Anal. 31 (5), 805-818.

Wooldridge, J.M., 2010. Econometric Analysis of Cross Section and Panel Data, 2nd ed. MIT Press, Cambridge, MA.

Yoder, J., Gebert, K.M., 2012. An econometric model for ex ante prediction of wildfire suppression costs. J. For. Econ. 18 (1), 76-89. 